\title{
Tonsillectomy - Orthodontics: Which sequences in children?
}

P. Garrec ${ }^{1}$, L. Jordan², N. Beydon ${ }^{3}$

1 Odontology Teaching and Research Unit, Paris-Diderot University - Orthodontics-Odontology Functional Unit, Pitié-Salpêtrière Hospital, Paris, France

2 Odontology Teaching and Research Unit, Paris-Diderot University - Child and Adolescent Treatment Functional Unit, Rothschild Hospital, Paris, France

${ }^{3}$ Respiratory Function and Sleep Functional Exploration Unit, Trousseau Hospital, Paris, France

\begin{abstract}
The most common cause of childhood obstructive sleep apnea syndrome (OSAS) is adenotonsillar hypertrophy. Aside from nocturnal symptoms, children with OSAS may present with lower school performance, behavioral disorder, cardiovascular complications and failure to thrive. First-line treatment is adenotonsillectomy; however, residual OSAS on postoperative polygraphy is reported in $20 \%$ to $40 \%$ of cases. In well-selected cases, orthodontic treatment can play an important role in the management of light to moderate childhood OSAS or residual OSAS after surgery, using growth activators or oral mandibular advancement appliances, rapid maxillary expansion and orofacial rehabilitation. Nevertheless, clinical studies with a high level of evidence of efficacy are lacking. To illustrate therapeutic sequences that may include an orthodontic phase, we present clinical cases encountered in our multidisciplinary outpatients clinic.
\end{abstract}

\section{KEYWORDS}

Obstructive sleep apnea syndrome, children, treatment, orthodontics

\section{INTRODUCTION}

Childhood obstructive sleep apnea syndrome (OSAS) affects $2 \%$ to $3 \%$ of the pediatric population. It is characterized by increased upper airway resistance due to pharyngeal narrowing, leading to episodic snoring, apnea or hypopnea. These events often cause intermittent hypoxia, hypercapnia and disordered sleep.
Without treatment, the consequences may include ${ }^{4}$.

- poor school performance (cognitive deficit);

- behavioral disorder (hyperactivity, aggression, attention deficit);

- cardiovascular impact (pulmonary hypertension, right cardiac insufficiency);

- growth disorder.

Address for correspondence:

Pascal Garrec

20 Rue Maurice Arnoux - 92120 Montrouge, France

E-mail: pascal.garrec@wanadoo.fr

Article received: 08-01-2015. Accepted for publication: 25-01-2015.

This is an Open Access article distributed under the terms of the Creative Commons Attribution License (http://creativecommons.org/licenses/by/4.0), which permits unrestricted use, distribution, and reproduction in any medium, provided the original work is properly cited. 


\section{RISK FACTORS FOR CHILDHOOD OSAS}

Risk factors comprise:

- nasal or pharyngeal anatomic obstruction or neuromuscular deficit of pharyngeal muscle tonus and reactivity;
- adenotonsillar hypertrophy, which is the main cause of onset of OSAS in children (fig. 1a and b).

In France, 35,000 tonsillectomies, associated to adenoidectomy in $82 \%$

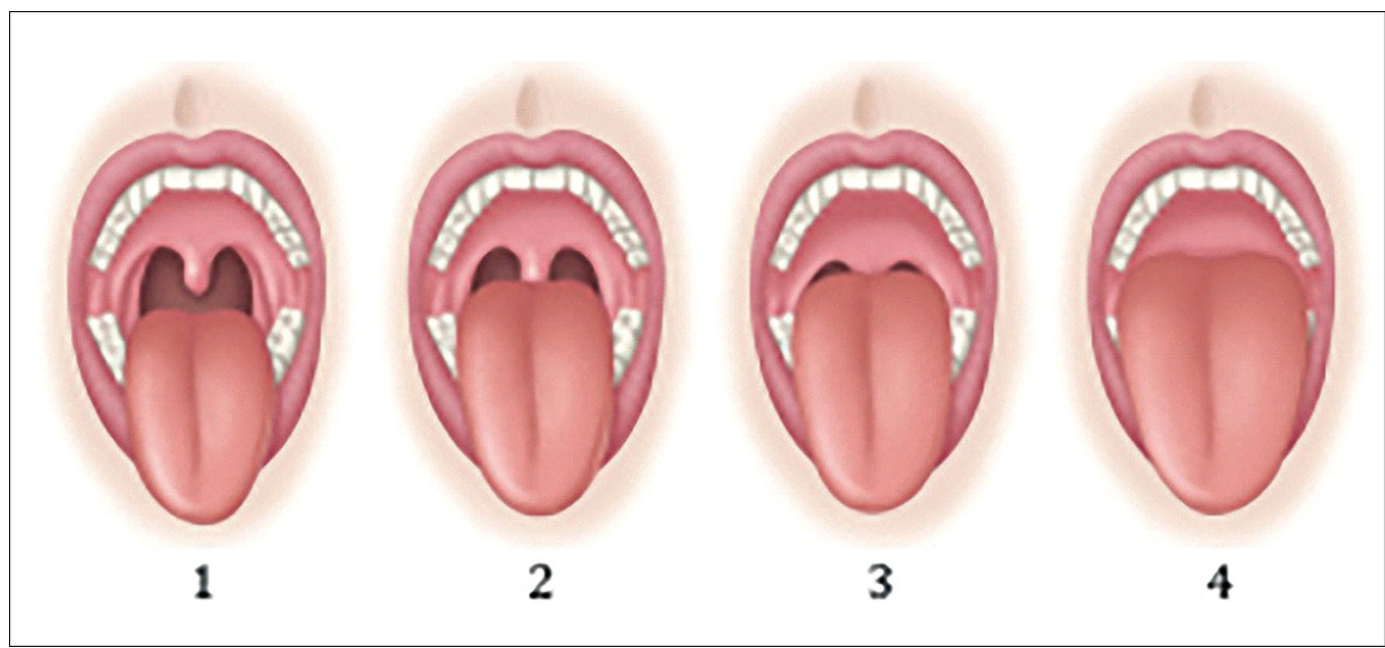

Figure 1a

Mallampati classification (1 to 4) assessing the "container/contents" relation: volume of tongue, soft palate and oral cavity; Class I: uvula and tonsils fully visible; Class II: uvula partly visible; Class III: Soft palate visible, uvula invisible; Class IV: only hard palate visible (see sciamsurgery. com, section 01/Chapter 03 Choice and Type of Anesthesia).

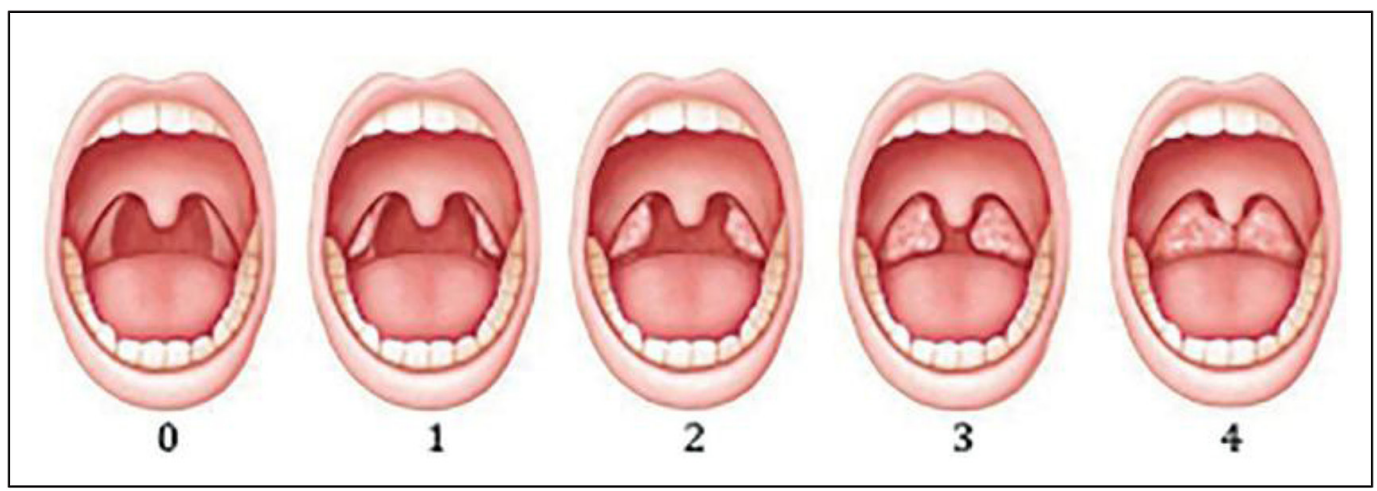

Figure $1 b$

Friedman classification (0 to 4), assessing palatine tonsil volume (see sleepmedicine-boardreview.files.wordpress.com); class 0: tonsils absent; class 1: tonsils hidden in fossa; class 2: tonsils protruding from fossa; class 3: tonsils protruding well beyond fossa but without crossing the midline; class 4: tonsils meeting at uvula. 
of cases, are performed yearly in children or adolescents $(<18$ years of age $)^{4}$. The number has been significantly decreasing for several years $(68,000$ in 2002), but the procedure continues to represent a high cost for the health system, with risks related to surgery and general anesthesia in children. Despite the high rate of primary tonsillectomies, little is known about their efficacy. The literature testifies to improvement in OSAS following adenotonsillectomy, but with a $20 \%$ to $40 \%$ rate of residual OSAS $^{1,2,7}$.
Certain factors are associated with recurrence or persistence of OSAS:

- initial severity;

- associated asthma or other chronic respiratory disease;

- ethnic predisposition;

- familial history of obstructive sleepdisordered breathing (OSDB);

- young age;

- obesity;

- neuromuscular involvement;

- craniofacial and orthodontic factors, whether or not included in a craniofacial dysmorphia syndrome.

The present article focuses on the last of these points.

\section{HOW CAN ORTHODONTICS AND ORTHOPEDICS CONTRIBUTE TO RESOLVING AIRWAY OBSTRUCTION, AND WHEN TO ACT?}

There have been several reports of anteriorization of the mandibular arcade in well-selected young patients (i.e., with mandibular retrusion); results were encouraging, but inconclusive due to small numbers $5,8,11$. Devices fixed to rings, inducing transverse expansion by activating the maxillary and palatine suture $^{6,9,10}$, increased nasopharyngeal volume $^{9}$ and proved relatively effective in well-selected subjects, although longterm assessment is lacking. Likewise, in another study, reinforcing the perioral and oral (lingual and velar) muscles was effective in resolving mild to moderate OSAS in adults ${ }^{3}$. There are thus no precise guidelines and the choice of treatment sequence is to be decided on a case-by-case basis, as shown in the present article by cases encountered in multidisciplinary (odontologists, orthodontists, ENT specialist and pedi- atrician) pediatric sleep consultation in the Trousseau Hospital (Paris, France).

\section{Case report 1: Rayan (5.5 years)} (fig. 2a, b, c)

- Referred by his ENT specialist for tonsillar hypertrophy.

- Clinical OSAS, with mild symptoms (cf. Table I).

- $115 \mathrm{~cm}, 22 \mathrm{~kg}$.

Conclusions and treatment decision:

- Sleep recording: pathological (severe OSAS; AHI 13, global respiratory events index 20.3).

- Adenotonsillectomy, May 2014.

- Postoperative sleep recording scheduled for residual symptoms.

- No dentofacial orthopedic treatment: no orthodontic or skeletal abnormalities. 


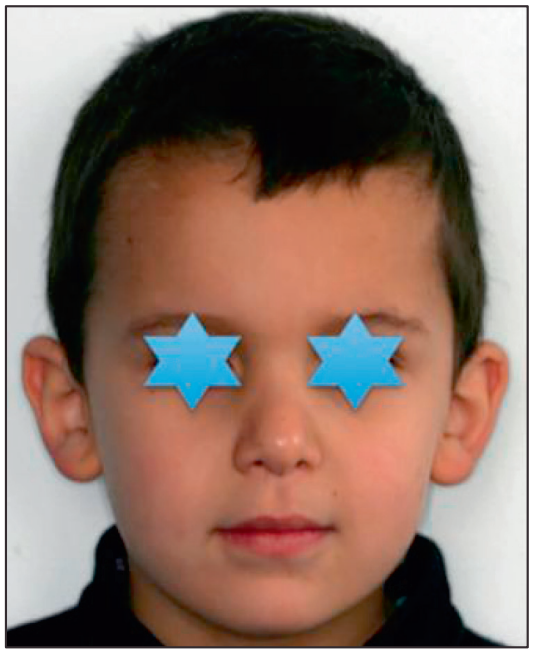

a

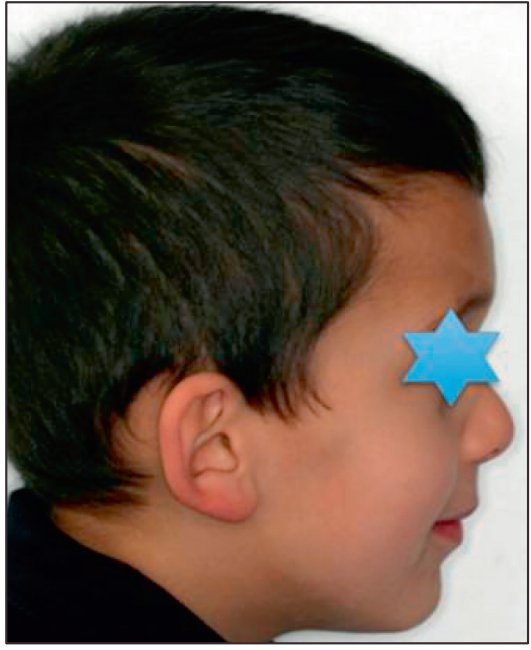

b

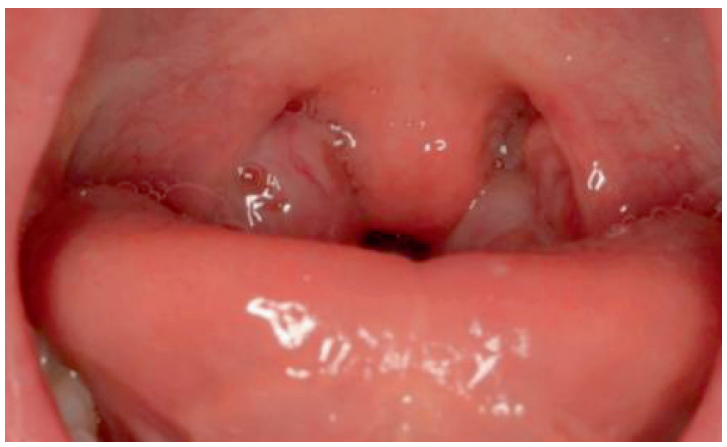

C

Figure $2 a, b$ and $c$

Case report 1. (a) AP and (b) lateral photographs of Rayan (5.5 years), referred for (c) Friedman 3 tonsillar hypertrophy, with only mild clinical OSAS.

Table I

\begin{tabular}{|l|l|}
\hline Nocturnal signs & Diurnal signs \\
\hline Snoring + & Difficulty awakening \\
\hline Sweats + & $\begin{array}{l}\text { Mild } \\
\text { concentration deficit (parents } \\
\text { and teachers) }\end{array}$ \\
\hline Agitated sleep & Oral respiration \\
\hline Labored breathing & $\begin{array}{l}\text { Doesn't listen to adults, } \\
\text { interrupts }\end{array}$ \\
\hline Respiratory breaks & Somnolence in class \\
\hline Enuresis & Mallampati : 2 \\
\hline Frequent awakening & \\
\hline Friedman : 3 & \\
\hline
\end{tabular}

Case report 2: Rony ( 7.5 years) (fig. 3a, b, c, d, e, f)

- Referred for snoring (cf. Table II).

- Clinical OSAS after tonsillectomy performed by ENT physician (cf. Table II).

- $124 \mathrm{~cm}, 26 \mathrm{~kg}$.

\section{Conclusions and treatment decision :}

- Discrepancy between clinically manifest OSAS and absence of ENT obstacle. 


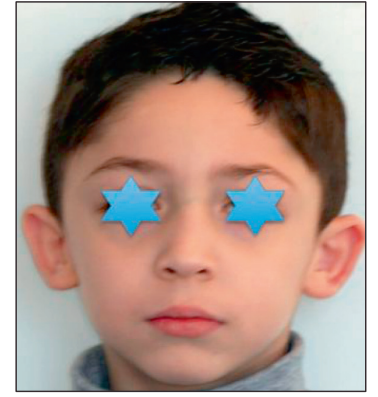

a

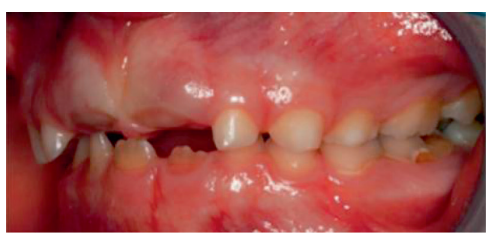

d

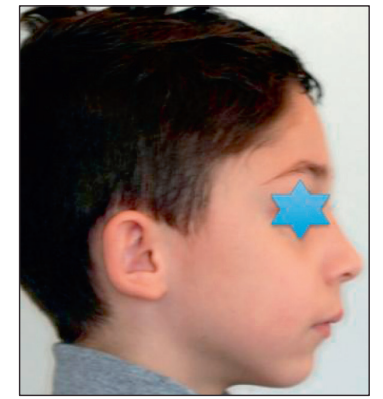

b

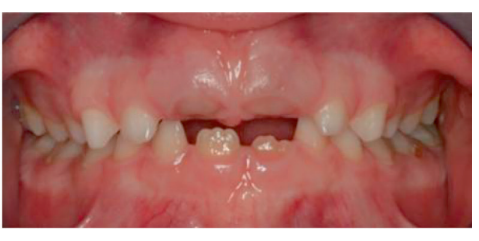

e

C
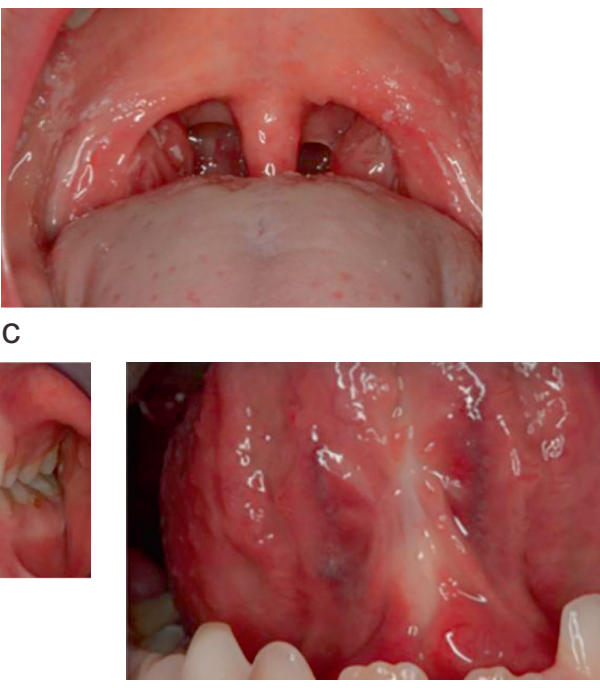

f

Figure $3 a, b, c, d, e, f$

Case report 2. a) AP and (b) lateral photographs of Rony (7.5 years), referred by ENT physician for persistent snoring after tonsillectomy. Retromandibulism and mandibular angle opening.

(c) Mild tonsillar hypertrophy, Friedman 1. $(d, e, f)$, dental class II with frenulum scar after surgery for bacterial infection.

- Sleep recording (moderate OSAS: AASM AHI, 6.5; global respiratory events index, 13.7).

- Orthopedic management feasible (retromandibulism and dental class II) with frenulum stretching.

Table /I

\begin{tabular}{|l|l|}
\hline Nocturnal signs & Diurnal signs \\
\hline Snoring +++ & Irritability and difficulty awakening \\
\hline Head extension & Daytime agitation \\
\hline Agitated sleep & Doesn't listen to adults, interrupts \\
\hline Labored breathing & $\begin{array}{l}\text { Concentration disrorder and motor } \\
\text { agitation (teacher's complaint) }\end{array}$ \\
\hline Respiratory breaks & $\begin{array}{l}\text { Follow-up in medical-psychological } \\
\text { center }\end{array}$ \\
\hline Respiration buccale & Mallampati : 4 \\
\hline Heavy sweats & \\
\hline Friedman : 1 & \\
\hline
\end{tabular}

\section{Case report 3: Damian (5 years) (fig. 4a, b, c, d, e)}

- Referred by pneumologist for discrepancy between clinical signs and ENT obstacles (cf. Table III).

- History of multiple nutritional allergy, infantile and childhood asthma.

- Sleeping with parents.

- $104 \mathrm{~cm}$, et $17 \mathrm{~kg}$.

\section{Conclusions and treatment decision:}

- Mild tonsillar hypertrophy (Friedman 1), discrepant with observed clinical signs (cf. Table III).

- Sleep recording (no OSAS; AASM AHI, 0.3; global respiratory events index, 1.1. Startled awakening at $10 \mathrm{pm}$; agitated awakening and tears at $11 \mathrm{pm}$ ). 

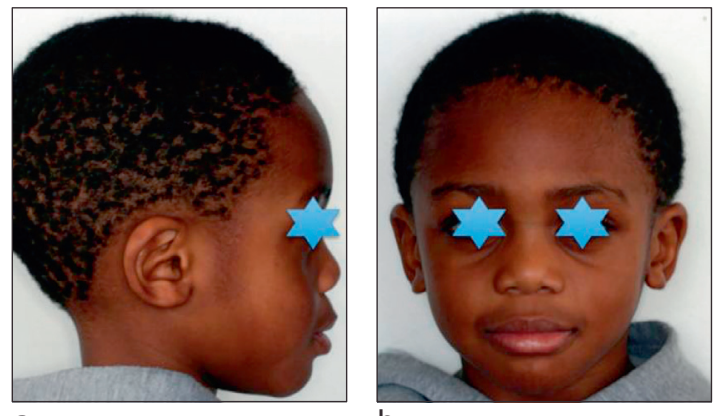

a

b

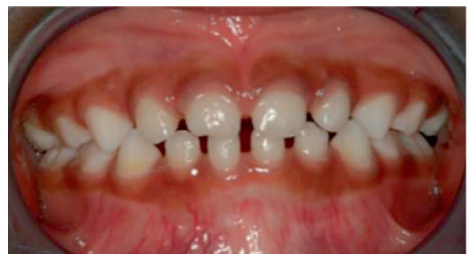

$\mathrm{C}$

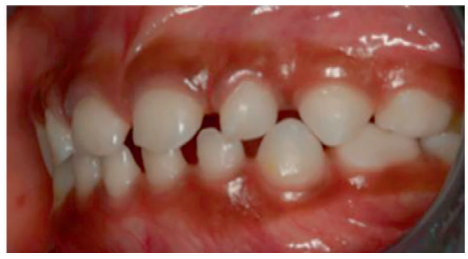

d

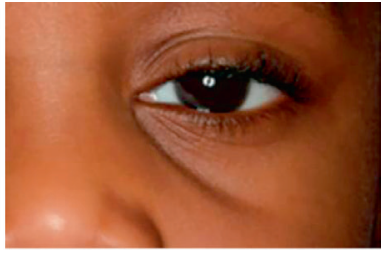

e

Figure $4 a, b, c, d, e$

Case report 3. (a) Lateral and (b) AP photographs of Damian (5 years), referred by pneumologist for discrepancy between clinical and ENT signs: i.e., small tonsils but strong symptoms.

(c, d) No orthodontic abnormality. (e) Signs of allergy (Dennie-Morgan).

- No dental or skeletal malocclusion.

- Proposed pedopsychiatric referral in pediatric reference center (for family environment).

Table III

\begin{tabular}{|l|l|}
\hline Nocturnal signs & Diurnal signs \\
\hline Moderate snoring & Oral breathing \\
\hline Labored breathing & Daytime agitation \\
\hline Difficulty passing air & $\begin{array}{l}\text { Moderate attention and } \\
\text { memory disorder }\end{array}$ \\
\hline Very frequent parasomnia & $\begin{array}{l}\text { Poor appetite, swallowing } \\
\text { difficult }\end{array}$ \\
\hline Enuresis & Somnolence \\
\hline Freequent nightmares & $\begin{array}{l}\text { Sortical and transverse anoma- } \\
\text { Agitated sleep }\end{array}$ \\
\hline Heavy sweats & $\begin{array}{l}\text { maxillary constriction) ogival } \\
\text { palate (not seen here). }\end{array}$ \\
\hline $\begin{array}{l}\text { Oral breathing (but chronic } \\
\text { allergic rhinitis) }\end{array}$ & Mallampati : 4 \\
\hline Friedman : 1 & \begin{tabular}{l} 
Intra-oral signs \\
\hline Extra-oral signs \\
\hline $\begin{array}{l}\text { Long face, signs of oral } \\
\text { breathing }\end{array}$
\end{tabular} \\
\hline
\end{tabular}

\section{Case report 4: Kahina (7 years) (fig. 5a, b, c, d)}

- Referred for residual clinical OSAS after tonsillectomy in 2011 (cf. Table IV).

- $112 \mathrm{~cm}, 21 \mathrm{~kg}$.

Table IV

\begin{tabular}{|l|l|}
\hline Nocturnal signs & Diurnal signs \\
\hline Snoring +++ & Morning tiredness \\
\hline Sweats + - & Somnolence (teacher) \\
\hline Agitated sleep & Irritability \\
\hline Oral breathing & Concentration disorder+++ \\
\hline Respiratory breaks & Oral breathing \\
\hline Difficulty breathing & \\
\hline Frequent awakening & \\
\hline Neck hyperextension & \\
\hline Friedman : 0 & Mallampati : $2 / 3$ \\
\hline
\end{tabular}




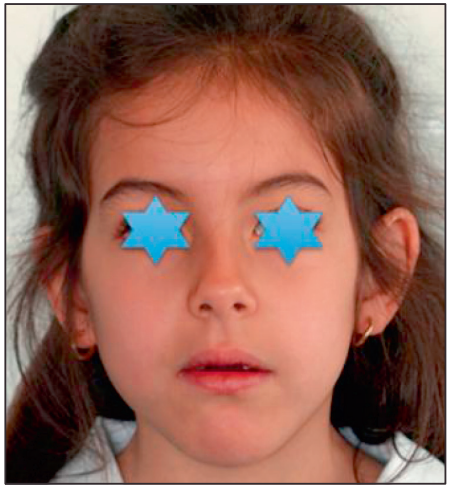

a

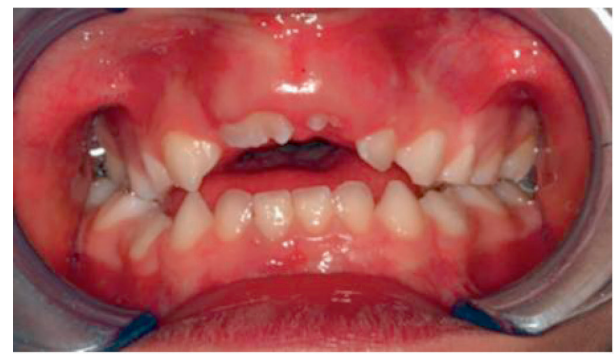

C

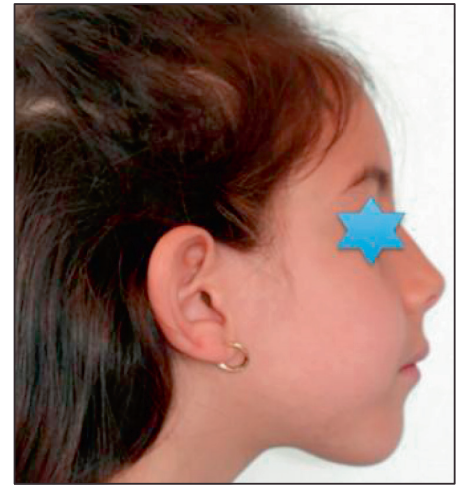

b

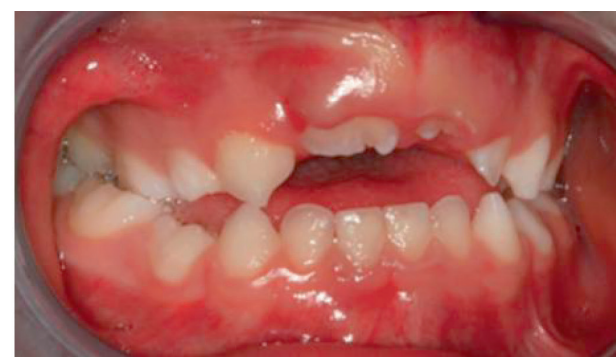

d

Figure $5 a, b, c, d$

Case report 4. (a) AP and (b) lateral photographs of Kahina (7 years), referred for residual clinical OSAS after adenotonsillectomy in 2011. Long face, signs of oral breathing, labial non-occlusion and lengthened lower face. (c, d) Vertical and transverse anomalies (anterior non-occlusion and maxillary constriction) and ogival palate (not visible here). Kahina presented with clinical OSAS

(cf. Table IV) not confirmed on sleep recording in 2014; however, strong snoring and upper airway resistance syndrome.

Conclusions and treatment decision:

- Non-pathologic sleep recording (no OSAS, but very high snoring index).
- Proposed orthopedic and functional treatment (intermaxillary disjunction and orofacial rehabilitation).

\section{DISCUSSION}

Interview and clinical examination of children with suspected OSAS are essential, to predict response to orthodontic/orthopedic and/or functional treatment: rehabilitation and functional envelope reinforcement.

- Examination of the face (symmetry and proportions between levels), frontally and laterally (chin position, laterally) discloses the 3D positioning of the skeletal foundations.

- Intra-oral examination:

- shape and depth of maxillary arcade (palate shape);

- dental relations (Angle's classification): 
- tongue position and palatine tonsil shape on Mallampati and Friedman scores (fig. 1a and b);

- anatomic particularities, especially bifid uvula indicating submucosal cleft.
- Functional examination: peri-oral muscle hypotonus; - oral breathing;

- tongue mobility (frenum) and resting position.

\section{CONCLUSION}

Certain patients presenting with mild to moderate OSAS or residual postoperative OSAS may benefit from orthodontic treatment, sometimes associated to orofacial rehabilitation, and should be correctly selected.
Orofacial muscular reinforcement to achieve lip closure at rest and nasal breathing should always be the aim.

\section{Conflict of interest: The authors declare no} conflicts of interest.

\section{REFERENCES}

1. Guilleminault C, Kasey KL, Khramtsov A, Pelayo R, Martinez S. Sleep disordered breathing: surgical outcomes in prepubertal children. Laryngoscope 2004;114:132-7.

2. Guilleminault C, Li K, Quo S, Inouye RN. A prospec- tive study on the surgical outcomes of children with sleep-disordered breathing. Sleep 2004;27:95-100.

3. Guimaraes KC, Drager LF, Genta PR, Marcondes BF, Lorenzi-Filho G. Effects of oropharyngeal exercises on patients with moderate obstructive sleep apnea syndrome. Am J Respir Crit Care Med 2009;179:962-6.

4. HAS 2012. Note de problématique : Amygdalectomie avec ou sans adénoïdectomie chez I'enfant ou l'adolescent (moins de 18 ans). www.has-sante.fr.

5. Holty JE C, et al. Maxillomandibular expansion and advancement for the treatment of sleep-disor- dered breathing in children and adults. Seminars in orthodontics 2012;18:162-70.

6. Monini $S$, et al. Rapid maxillary expansion for the treatment of nasal obstruction in children younger than 12 years. Arch Otolaryngol Head Neck Surg 2009;135:22-7.

7. Tauman $\mathrm{R}$, et al. Persistence of obstructive sleep apnea syndrome in children after adenotonsillectomy. J Pediatr 2006;149:803-8.

8. Villa MP,BernkopfE, PaganiJ, BroiaV,Montesano M, Ronchetti R. Randomized controlled study of an oral jaw-positioning appliance for the treatment of obstruc- tive sleep apnea in children with malocclusion. Am J Respir Crit Care Med 2002;165:123-7.

9. Villa MP, et al. Rapid maxillary expansion in children with obstructive sleep apnea syndrome: 12-month follow-up. Sleep Med 2007;8:128-34.

10. Villa MP, Rizzoli A, Miano S, Malagola C. Efficacy of rapid maxillary expansion in children with obstructive sleep apnea syndrome: 36 months of follow-up. Sleep Breathe 2011;15:179-84.

11. Zhang $\mathrm{C}, \mathrm{He} \mathrm{H}, \mathrm{Ngan}$ P. Effects of twin block appliance on obstructive sleep apnea in children: a preliminary study. Sleep Breathe 2013;17:1309-14. 